\title{
Relationship of Colominic Acid (Poly $N$-Acetylneuraminic Acid) to Bacteria which Contain Neuraminic Acid
}

\author{
BY G. T. BARRY, VELLA ABBOTT AND T. TSAI \\ University of Tennessee Memorial Research Center, Knoxville, Tennessee, U.S.A.
}

(Received 10 February 1962)

\begin{abstract}
SUMMARY
The bacteriocinic strain of Escherichia coli known as $\mathbf{K 2 3 5 L}+\mathrm{OC}^{+}$which elaborates colominic acid (poly $N$-acetylneuraminic acid) possesses a $\mathrm{K}$ antigen and has the serotype $E$. coli $01: K 1: H N M$ in accordance with the Kauffmann-White classification scheme of the enterobacteriaceae. Strains of $E$. coli with $01: \mathrm{K} 1: \mathrm{HNM}$ or $02: \mathrm{K1}: \mathrm{HNM}$ serotype elaborate a similarly constituted colominic acid. Chemical analysis has revealed that all $E$. coli with a K1 serotype contain neuraminic acid, but that strains which have other $\mathrm{K}$ serotypes do not contain significant amounts of this substance. The nature of the $\mathbf{O}$ serotype and the ability to produce haemolysins or bacteriocines are unrelated to the presence of neuraminic acid in the various strains analysed. Thus, the close association between a K1 serotype and colominic acid in $\boldsymbol{E}$. coli suggests that all strains of this serotype produce colominic acid. Salmonella dahlem, $\boldsymbol{S}$. djkarta, E. coli O1O:K5:HNM, Group C Neisseria meningitidis 1908 and 1935, and Citrobacter freundii O5:H3O ( $E$. coli 5396/38) contain neuraminic acid as shown by chemical tests. However, the neuraminic acid is firmly bound and polysaccharides containing this material are not readily elaborated. As no serological relationship exists between these strains and strains of $E$. coli having a K1 serotype, it is concluded that they are non-producers of colominic acid. Thus, bacteria of various genera which contain neuraminic acid have this substance in different chemical combinations.
\end{abstract}

\section{INTRODUCTION}

Numerous investigators have been concerned with the problem of isolation and purification of large molecular weight substances derived from bacteria. These materials, constituted of protein, polysaccharide and lipid, often are shown to be homogeneous macromolecules upon application of physical and chemical criteria. Little is known, however, concerning the specific nature of the chemical binding of protein to carbohydrate in these 'lipoprotein carbohydrate' complexes. With the discovery in recent years of the presence of the acidic amino sugars, muramic acid (3-0- $\alpha$-carboxyethylglucosamine) (Strange \& Powell, 1954) and neuraminic acid (Barry, 1958) in products of bacterial origin, the possibility is presented that these monosaccharides which are hybrids between simple sugars and amino acids may play an essential role in the linking of proteins to carbohydrates. Evidence indicates that muramic acid is linked to other monosaccharides and to amino acids in bacterial cell walls of a large variety of Gram-positive micro-organisms (Cummins $\&$ Harris, 1956). However, the demonstration that neuraminic acid also plays an 
important role in the composition of bacterial cell walls or of other components of bacteria has yet to be established.

Up to the present time few micro-organisms have been shown to contain derivatives of neuraminic acid. Colominic acid, a unique polymer constituted primarily, if not solely, of units of $N$-acetylneuraminic acid, is the first polysaccharide obtained from bacterial origin shown to contain a neuraminic acid derivative (Barry, 1957, 1958). This polysaccharide was isolated from an Escherichia coli culture filtrate. The isolation of a second polysaccharide, also primarily constituted of units of $\mathrm{N}$-acetylneuraminic acid, was subsequently reported from strains of Group C Neisseria meningitidis (Watson, Marinetti \& Scherp, 1958). It was first noted in this laboratory (Barry, 1959; Barry, Tsai \& Chen, 1960) that neuraminic acid forms a considerable portion of the chemical composition of a strain of Citrobacter freundii. The detection of neuraminic acid in two related strains, Salmonella dahlem and $S$. djkarta, has also been reported (Westphal, Kauffmann, Luderitz \& Stierlin, 1960).

As the distribution of the neuraminic acids among the various species of bacteria is largely unknown, it was the purpose of the present investigation to extend our knowledge concerning the presence of these acids in other micro-organisms. Detection of neuraminic acid or its derivatives in several species of bacteria would materially aid in the establishment of these substances as essential structural components of cells and aid in the determination of their function in microorganisms.

\section{METHODS}

Organisms. In the following experiments several strains of micro-organisms were employed. A variant strain of Escherichia coli designated as $\mathrm{K} 235 \mathrm{~L}+\mathrm{OC}^{+}$was derived from an $E$. coli known as K235 obtained from Dr Pierre Fredericq of the University of Liège, Belgium. A strain known as $\boldsymbol{E}$. coli 5396/38 obtained from the Walter Reed Army Medical School, Washington, D.C. was kindly provided by Dr Maurice Landy and Dr Marion. Webster. The latter also provided transfers of Salmonella typhi Ty 2 and Ballerup strain 7851/39. A strain of S. enteritidis and two strains of $S$. paratyphi were provided by Dr Frank Holtman, University of Tennessee, Knoxville, Tennessee. Most of the other strains of $E$. coli and Salmonella were kindly sent us by Dr W. H. Ewing, United States Public Health Service, Chamblee, Georgia. Two strains of Group C Neisseria meningitidis known as 1908 and 1935 were obtained from Dr H. Scherp, National Institutes of Health, Bethesda, Maryland, and from Dr Glen Watson, Bowman Gray Medical School, WinstonSalem, North Carolina. The strains of Phase I and Phase II Shigella sonnei originated from the laboratory of Dr Sarah Branham, Walter Reed Army Medical School, Washington, D.C. and the Bacillus megaterium strains KM and 899a from the laboratory of Dr John H. Northrup in California. Several miscellaneous strains of Salmonella, Bacillus cereus, Proteus vulgaris, Aerobacter aerogenes, Serratia marcescens, Rhodopseudomonas palustris, Escherichia coli and Haemophilus influenzae Type B and $\mathrm{D}$ were sent to this laboratory by different investigators for determination of neuraminic acid content. These are, for the most part, incompletely characterized strains of unknown origin.

Antisera. Antisera were obtained from rabbits which had received multiple 
intravenous injections of formalized bacteria followed by inoculations with viable cells in accordance with the procedures described by Edwards (1951) and Edwards \& Ewing (1955) for enteric micro-organisms. Antisera against Group C Neisseria meningitidis were prepared by the procedure of Rake (1933).

Media and cultivation of organisms. Strains of Group C Neisseria meningitidis were maintained on blood agar slopes, while large numbers of organisms were harvested from blood agar plates. Both slopes and plates were incubated for $6 \mathrm{hr}$. or $18 \mathrm{hr}$. at $37^{\circ}$ in a candle jar at low oxygen tension.

Strains of enteric bacteria were maintained on nutrient agar slopes incubated for $16 \mathrm{hr}$. at $37^{\circ}$; larger numbers of cells were cultivated at $37^{\circ}$ at $\mathrm{pH} 7.0$ in a $1 \%(\mathrm{w} / \mathrm{v})$ dialysed casamino acid medium (Difco) enriched with dialysed yeast extract, $0.5 \%(w / v)$ (Difco), and glucose $1.7 \%(w / v)$ contained in 2 litre flasks or in 5-gallon pyrex glass bottles (Barry, 1958).

Strains of Haemophilus influenzae were cultivated with aeration at $37^{\circ}$ for $6 \mathrm{hr}$. in a $3.7 \%(\mathrm{w} / \mathrm{v})$ brain heart infusion broth (Bacto) enriched by addition of supplement B yeast extract (Bacto, $1 \mathrm{ml} . / 100 \mathrm{ml}$.) (Neter, 1947).

Rhodopseudomonas palustris was cultivated without aeration at $\mathbf{2 2}^{\circ}$ for $48 \mathrm{hr}$. in a dialysed $1 \%(\mathrm{w} / \mathrm{v})$ casamino acid medium. A $200 \mathrm{~W}$. tungsten lamp placed 6 in. away from the flask illuminated the culture during the growth period.

Biological preparations. The Group C Neisseria meningitidis hapten employed, generously supplied by Dr Glen Watson, contained $\mathbf{7 0} \%$ of $\mathrm{N}$-acetylneuraminic acid by our analysis.

Chemical analyses. Protein analyses were made by a modified procedure of Folin and Ciocalteu (Kunkel \& Tiselius, 1951) and carbohydrate by a modified anthrone method (Goebel \& Barry, 1958). Hexosamine was determined by the procedure of Sorensen (1938); hexuronic acids and pentoses were determined by the methods of Dische (1947) and Dische, Shettles \& Osnos (1949).

A modified Ehrlich procedure employed for the detection and estimation of neuraminic acid was carried out as follows. To a ml. sample of an aqueous solution of substance containing $0.05-0.50 \mathrm{mg}$. of neuraminic acid were added $2 \mathrm{ml}$. of $30 \%$ (w/v) $\mathrm{Al}_{2}\left(\mathrm{SO}_{4}\right)_{3} \cdot \mathbf{1 8 H}_{2} \mathrm{O}$ solution and $1 \mathrm{ml}$. of Ehrlich reagent $(5 \mathrm{~g}$. $p$-dimethylaminobenzaldehyde $/ 50 \mathrm{ml}$. concentrated hydrochloric acid $+50 \mathrm{ml}$. water $(\mathrm{w} / \mathrm{v}))$. A control tube ( $1 \mathrm{ml}$. of water + reagents ) was also prepared. The covered tubes were heated at $100^{\circ}$ for $30 \mathrm{~min}$. in a boiling-water bath. The tubes were rapidly cooled and optical density readings taken in a Beckman spectrophotometer at $530 \mathrm{~m} \mu$ against the control tube contents. The \% neuraminic acid was calculated using a reference curve in which $\mathrm{N}$-acetylneuraminic acid (ovine sialic acid) served as a standard. The advantage of this modified Ehrlich procedure over that originally reported by Werner \& Odin (1952) is that a more stable colour complex is formed in the presence of $\mathrm{Al}^{3+}$ cation, and the sensitivity of the method is increased by approximately twofold. It should also be noted that the absorption maximum is shifted from 565 to $530 \mathrm{~m} \mu$ by this change in procedure. In addition to the above procedure, a modified orcinol method (Barry, 1958) was used for the detection of the neuraminic acids.

Biological analyses. Bacteria were tested for their ability to produce bacteriocines as follows. A stab culture of the organism grown on an agar plate for $48 \mathrm{hr}$. was killed by the addition of $0.5 \mathrm{ml}$. of chloroform to the cover of the Petri dish. The 
dish was incubated for $1 \mathrm{hr}$. at $37^{\circ}$ to evaporate the chloroform. An overlay of $3 \mathrm{ml}$. of nutrient soft agar seeded with one drop of a $3 \mathrm{ml}$. slant wash of the indicator strain (Escherichia coli strain B, Phase I Shigella sonnei or Salmonella enteritidis) was poured over the stab culture and the plates incubated overnight at $37^{\circ}$ after which readings were made. A clear area around the killed stab culture was taken as a positive test.

Agglutination tests of enteric organisms were conducted in the ordinary manner employing cells obtained from $18 \mathrm{hr}$. nutrient broth cultures. The bacteria were centrifuged, washed in isotonic saline, and resuspended in isotonic saline to a concentration of $2 \times 10^{8} / \mathrm{ml}$. The titres were read after incubation at $37^{\circ}$ for $2 \mathrm{hr}$. and after standing overnight at $4^{\circ}$. In all instances, control experiments utilizing similar dilutions of the corresponding normal sera were included in the tests.

Agglutination tests using Group C Neisseria meningitidis were conducted by the procedure described by Watson \& Scherp (1958).

Univalent anti $\mathbf{K}$ antisera was prepared by incubation of whole Escherichia coli antisera at $37^{\circ}$ with heat-killed cells. This procedure was repeated until no agglutination of heated $E$. coli cells was detectable by agglutination tests. Usually three cycles of absorption were sufficient to remove $O$ agglutinins.

Precipitin tests were conducted as follows. To a series of small tubes $(5 \mathrm{~mm} . \times 50 \mathrm{~mm}$.) was added $0.15 \mathrm{ml}$. of undiluted serum followed by an overlay of $0.15 \mathrm{ml}$. of serial 10 fold dilutions of test substance dissolved in isotonic saline. After standing for $2-4 \mathrm{hr}$, at room temperature $\left(22^{\circ}-25^{\circ}\right)$, the tubes were read for the presence of a precipitate ring at the interface of the two solutions. In all tests, control tubes were included in each series employing normal serum with isotonic saline and normal serum with an isotonic saline solution of the material to be tested.

Haemagglutination tests were conducted by the procedure of Landy \& Lamb (1953) employing human $O$ erythrocytes obtained from the blood bank of the University of Tennessee Memorial Hospital.

Haemagglutination blocking tests were conducted as follows. To each of a series of tubes containing $0.5 \mathrm{ml}$. of an isotonic solution of test substance of $20,4,0.5$ and $0.2 \mathrm{mg}$. concentration was added $0.5 \mathrm{ml}$. antiserum. The tubes were incubated at $37^{\circ}$ for $2 \mathrm{hr}$. A control tube containing $0.5 \mathrm{ml}$. of antiserum and $0.5 \mathrm{ml}$. isotonic saline was also incubated. After incubation, the contents of each tube were diluted $1 / 5$ by addition of $4 \mathrm{ml}$. of isotonic saline. The antiserum in each tube was now equivalent to a 1/10 dilution. Serial two fold dilutions were made in isotonic saline from the control tube and from each of the four tubes containing the test substance and diluted antiserum mixture. To five series of tubes containing $0.2 \mathrm{ml}$. of each dilution of antiserum was added $0.2 \mathrm{ml}$. of sensitized human type $\mathrm{O}$ erythrocytes. All tubes were incubated at $\mathbf{3} 7^{\circ}$ for $2 \mathrm{hr}$. after which readings were taken.

Bacterial counts were made by the poured plate assay technique on nutrient agar using $0 \cdot 1 \mathrm{ml}$. aliquots of a $10^{-5}$ and $10^{-6}$ broth dilution of the culture. The plates were incubated overnight at $37^{\circ}$ after which readings were made (Adams, 1950).

Haemolysins were detected by streaking the organism on nutrient blood agar plates which contained fresh sheep cells in a concentration of $1.0 \%(w / v)$. The plates were incubated for $16 \mathrm{hr}$. at $37^{\circ}$ after which readings were made. The appearance of a clear area or a greenish zone along the streak or surrounding individual colonies indicated a positive test. 


\section{Technique for detection and estimation of neuraminic acid in bacteria}

Detection in $\boldsymbol{K}$ antigens of Escherichia coli. To a litre of nutrient medium containing $1 \%(\mathrm{w} / \mathrm{v})$ of dialysed casamino acids, $(5 \cdot 0 \mathrm{~g}$. dialysed yeast extract in $10 \mathrm{ml}$. water and $20 \mathrm{ml}$. $50 \%$, w/v, dextrose) adjusted to $\mathrm{pH} 7 \cdot 0$ with $0.1 \mathrm{~N}$ phosphate buffer was seeded $0.2 \mathrm{ml}$. of a $3 \mathrm{ml}$. slope wash of micro-organism. The culture was grown with aeration for $5 \mathrm{hr}$. or $18 \mathrm{hr}$. at $37^{\circ}$. Five ml. of chloroform was added to kill the culture and aeration continued for an additional $15 \mathrm{~min}$. Bacteria were collected by centrifugation, washed in $10 \mathrm{ml}$. distilled water, collected as before, and resuspended in $10 \mathrm{ml}$. distilled water. The wash was set aside for analysis. Two ml. of the bacterial suspension was heated in a sealed tube for $2 \frac{1}{2} \mathrm{hr}$. at $100^{\circ}$ in a water bath, and $2 \mathrm{ml}$. was maintained at room temperature $\left(22^{\circ}-25^{\circ}\right)$ to serve as a control. Both the heated and unheated samples were centrifuged at $10,000 \mathrm{~g}$ for $30 \mathrm{~min}$. and the clear supernatants removed by pipette. Analyses for neuraminic acid were performed on $1 \mathrm{ml}$. samples of the heated supernatant employing the modified procedure of Ehrlich. The unheated supernatant served as a control in the analysis. If the solutions were turbid after heating with the analytical reagents, they were rapidly filtered through Whatman no. 1 paper before readings were made at $530 \mathrm{~m} \mu$ in the Beckman spectrophotometer. In cases where a quantitative evaluation of the amount of neuraminic acid was made, the analytical values obtained for content of neuraminic acid of the wash and supernatant from the heated bacteria were combined and recorded as a single value.

Estimation of neuraminic acid in dried bacteria. When whole bacteria were analysed for content of neuraminic acid, the cells obtained from a litre of culture were lyophilized after washing. Yields of $300-400 \mathrm{mg}$. of dried cells were usually obtained. The analytical values obtained for content of neuraminic acid of the dried cells and of the cell wash were combined and recorded as a single value.

\section{RESULTS}

\section{Agglutination properties of Escherichia coli $\mathrm{K}_{235 L}+\mathrm{OC}^{+}$}

As the bacteriocinic strain of Escherichia coli $\mathbf{K 2 3 5 L}+\mathrm{OC}^{+}$was the first microorganism described which produces a substance containing a derivative of neuraminic acid, namely colominic acid, it was of interest to learn more about the properties of this bacterium. It was soon apparent that viable $E$. coli $\mathbf{K 2 3 5 L}+\mathrm{OC}^{+}$was not readily agglutinated in homologous antiserum. According to Kauffmann (1943), such non-agglutinable strains of $\boldsymbol{E}$. coli contain a capsule which surrounds the micro-organism and prevents $O$ agglutination. Heating such organisms removes the so-called anti $O$ agglutination inhibitor; and following this treatment, $\mathrm{O}$ agglutination readily occurs in homologous antisera. The agglutination inhibitor is termed a $\mathrm{K}$ antigen (Kauffmann, 1943).

Agglutination experiments of Escherichia coli $\mathrm{K} 235 \mathrm{~L}+\mathrm{OC}^{+}$in whole $E$. coli K235L $+\mathrm{OC}^{+}$antibacterial antisera and in antisera absorbed with heat killed cells were used to establish the presence of a $\mathbf{K}$ antigen.

The results of all agglutination tests are shown in Table 1 where it is seen that the unheated viable cells of Escherichia coli $\mathbf{K 2 3 5 L}+\mathrm{OC}^{+}$are strongly agglutinated to a titre of $1 / 64$ in unabsorbed antibacterial antiserum; whereas, the heated cells 
show an agglutination titre greater than $1 / 4096$. It is to be noted that viable cells show strong agglutination to a titre of $1 / 32$ in antiserum from which the $O$ agglutinins were removed by absorption with heated cells. These results clearly demonstrate that $\boldsymbol{E}$. coli $\mathrm{K} 235^{+} \mathrm{OC}^{+}$contains a heat labile agglutination inhibitor commonly termed a $\mathrm{K}$ antigen (Kauffmann, 1943).

Confirmation of the presence of a $\mathrm{K}$ antigen in Escherichia coli $\mathbf{K 2 3 5 L}+\mathrm{OC}^{+}$was obtained after submission of the organism for classification of serotype which was found to be $E$. coli 01:K1:HNM, in accordance with the Kauffmann-White classification scheme for identification of enterobacteriaceae.

Table 1. Agglutination of Escherichia coli $\mathrm{K235L}^{+} \mathrm{OC}+$ in homologous antiserum and in antiserum absorbed with heated $\mathrm{E}$. coli $\mathrm{K}_{235 L} \mathrm{OCC}^{+}$

\begin{tabular}{|c|c|c|c|c|c|c|c|c|c|c|c|}
\hline \multirow[b]{2}{*}{ Bacteria } & \multirow{2}{*}{$\begin{array}{c}\text { Antibacterial } \\
\text { antiserum }\end{array}$} & \multicolumn{10}{|c|}{ Dilution of antiserum } \\
\hline & & $1 / 8$ & $1 / 16$ & $1 / 32$ & $1 / 64$ & $1 / 128$ & $1 / 25$ & $1 / 512$ & $1 / 1024$ & $1 / 2048$ & $1 / 4096$ \\
\hline Viable & Absorbed & 4 & 4 & 4 & 3 & 2 & $\mathbf{0}$ & $\mathbf{0}$ & $\mathbf{0}$ & $\mathbf{0}$ & $\mathbf{0}$ \\
\hline Heat killed & Absorbed & $\mathbf{0}$ & $\mathbf{0}$ & $\mathbf{0}$ & $\mathbf{0}$ & $\mathbf{0}$ & $\mathbf{0}$ & $\mathbf{0}$ & $\mathbf{0}$ & $\mathbf{0}$ & $\mathbf{0}$ \\
\hline Viable & Unabsorbed & 4 & 4 & 4 & 4 & 3 & 0 & 0 & 0 & 0 & 0 \\
\hline Heat killed & Unabsorbed & 4 & 4 & 4 & 4 & 4 & 4 & 4 & 4 & 4 & 1 \\
\hline
\end{tabular}

Detection of neuraminic acid, bacteriocine and haemolysin in Escherichia coli of known serotype. As nothing was known concerning the biological function of neuraminic acid or of its polymer, colominic acid, in $E$. coli $\mathrm{K} 235 \mathrm{~L}+\mathrm{OC}^{+}$, attempts were made to correlate the presence of neuraminic acid with other known properties of the bacterium. The presence of a $\mathbf{K}$ antigen in $E$. coli $\mathbf{K 2 3 5} \mathrm{L}^{+} \mathrm{OC}+$ suggested that other inagglutinable strains of $\boldsymbol{E}$. coli which have a $\mathbf{K}$ antigen might also elaborate colominic acid-like substances. Accordingly, a series of $\boldsymbol{E}$. coli strains of known $\mathbf{O}$ and $\mathbf{K}$ serotypes was analysed for the presence of neuraminic acid, bacteriocine and haemolysin.

Heat treatment of inagglutinable strains of Escherichia coli permits $\mathrm{O}$ agglutination to occur in homologous antibacterial antisera. It is apparent that the anti$\mathbf{O}$ agglutination factor, presumably the $\mathbf{K}$ antigen, which surrounds the microorganism, is removed from the bacterial surface by the heating procedure. Therefore, chemical analysis of supernatants obtained after centrifugation of heated cells can be used to ascertain if neuraminic acid forms an appreciable part of the chemical composition of the $\mathbf{K}$ antigen of the organism.

The results of the analyses for neuraminic acid, bacteriocine and haemolysin in various strains of Escherichia coli are recorded in Table 2. Detection of neuraminic acid was made in only two of the nineteen strains analysed, E. coli O1:K1:HNM and E. coli O1O:K5:HNM. Haemolysins were produced by three strains and bacteriocines were elaborated by seven strains.

It must be concluded, therefore, that neuraminic acid does not form an appreciable portion of the chemical composition of $\mathbf{K}$ antigens of Escherichia coli. However, the limitations of the chemical procedure do not exclude the presence of trace amounts of the neuraminic acids in $\mathbf{K}$ antigens of $E$. coli where they may play an important role in the linkage of carbohydrates to proteins or peptides in these 
materials. In addition, it may be noted that no correlation exists between the presence of neuraminic acid and the haemolytic or bacteriocinic properties of the micro-organisms. The bacteriocinic and haemolytic properties are similarly unrelated to each other.

Table 2. Escherichia coli analysed for neuraminic acid haemolysin and bacteriocine

\begin{tabular}{|c|c|c|c|c|c|}
\hline \multirow[b]{2}{*}{ Organism tested } & \multirow{2}{*}{$\begin{array}{l}\text { Neuraminic } \\
\text { acid }\end{array}$} & \multirow[b]{2}{*}{ Haemolysin } & \multicolumn{3}{|c|}{ Test organism for bacteriocine } \\
\hline & & & E. $\operatorname{coli}^{\prime} \mathrm{B}$ ' & S. enteri & $\stackrel{\text { Sh.sonnei }}{ }$ \\
\hline E. coli O1:K1:HNM & + & - & + & - & - \\
\hline E. coli O6:K53:HNM & - & + & + & - & - \\
\hline E. coli O2O:K17:HNM & - & - & - & - & - \\
\hline E. coli O1O:K5:HNM & + & - & - & - & - \\
\hline E. coli O4:K12:HNM & - & + & + & - & - \\
\hline E. coli O21:K20:HNM & - & - & - & - & - \\
\hline E. coli O11:K10:HNM & - & - & - & - & - \\
\hline E. coli $\mathrm{O} 8: \mathrm{K} 44: \mathrm{HNM}$ & - & - & + & - & - \\
\hline E. coli O9:K29:HNM & - & - & + & - & - \\
\hline E. coli O9:K55:HNM & - & - & - & - & - \\
\hline E. coli O9:K35:HNM & - & - & - & - & - \\
\hline E. coli O9:K38:HNM & - & - & - & - & - \\
\hline E. coli O9:K33:HNM & - & - & - & - & - \\
\hline E. coli $\mathrm{O} 26: \mathrm{K} 60: \mathrm{HNM}$ & - & + & - & - & - \\
\hline E. coli O127a:K63:HNM & - & - & - & - & - \\
\hline E. coli O86a:K61:HNM & - & - & - & + & - \\
\hline E. coli O111ab:K58:HNM & - & - & + & - & - \\
\hline E. coli O112ac:K66:HNM & _- & - & - & - & - \\
\hline E. coli O55:K59:HNM & - & - & - & - & - \\
\hline
\end{tabular}

Detection of neuraminic acid, bacteriocine and haemolysin in various Escherichia coli which have a $K 1$ and various $O$ serotypes. As shown previously, the serotype of Escherichia coli $\mathrm{K}^{235 \mathrm{~L}}+\mathrm{OC}^{+}$was determined as $\boldsymbol{E}$. coli $\mathrm{O1}: \mathrm{K1}: \mathrm{HNM}$. If the $\mathrm{K}$ serotype of the organism is related to the presence of neuraminic acid, then different strains of $E$. coli which possess in common a $\mathrm{K} 1$ combined with different $O$ serotypes should contain neuraminic acid. Accordingly, five strains of $E$. coli, all containing a $\mathrm{KI}$ and different $\mathrm{O}$ serotypes, were analysed for neuraminic acid, bacteriocine and haemolysin. The results are given in Table 3 ; it may be noted that all five strains tested contain neuraminic acid. Three of the strains tested show haemolytic properties, and four elaborate bacteriocine.

It is concluded that all Escherichia coli which possess a K1 serotype contain a derivative of neuraminic acid and that the haemolytic or bacteriocinic properties which may be associated with the bacteria are unrelated to the presence or absence of this substance.

Neuraminic acid content of various Escherichia coli as percentage of dry weight. Although neuraminic acid was shown by qualitative tests to form part of the chemical composition of strains of Escherichia coli with a $\mathrm{Kl}$ serotype, it was of interest to ascertain whether these different strains contain equivalent amounts of neuraminic acid. Bacteria harvested from cultures during the logarithmic phase and the final phase of growth were dried and analysed for content of neuraminic acid. The data recorded in Table 4 show typical analytical values obtained for content of neuraminic acid determined as percentage of dry weight. It is evident that all strains of $E$. coli analysed contain approximately equivalent amounts of 
neuraminic acid if cultivated and harvested under similar conditions. However, bacteria obtained during the logarithmic phase contain a higher percentage of neuraminic acid than do mature bacteria isolated in the final phase of growth. Thus, it is apparent that neuraminic acid itself or substances containing neuraminic acid are elaborated into the culture medium during growth of these strains.

Table 3. Escherichia coli with $a K 1$ and various $O$ serotypes analysed for neuraminic acid, haemolysin and bacteriocine

\begin{tabular}{|c|c|c|c|c|c|}
\hline \multirow[b]{2}{*}{ Organism tested } & \multirow{2}{*}{$\begin{array}{c}\text { Neuraminic } \\
\text { acid }\end{array}$} & \multirow[b]{2}{*}{ Haemolysin } & \multicolumn{3}{|c|}{ Test organism for bacteriocine } \\
\hline & & & E. $\operatorname{coli}$ ' $\mathbf{B}$ ' & S. enteri & Sh.sonnei \\
\hline O1:K1:HNM & + & + & + & $\rightarrow$ & - \\
\hline i O2:K1:HNM & + & + & + & - & - \\
\hline$i$ O7:K1:HNM & + & $t$ & + & - & - \\
\hline$i$ 016:K1:HNM & + & - & - & - & - \\
\hline O25:K1:HNM & + & - & - & - & + \\
\hline
\end{tabular}

Table 4. Neuraminic acid content of Escherichia coli with a $K 1$ and various $O$ serotypes grown at $37^{\circ}$ and harvested after $5 \mathrm{hr}$. or $18 \mathrm{hr}$.

\begin{tabular}{lcc} 
& \multicolumn{2}{c}{$\begin{array}{c}\text { Neuraminic acid in percentage } \\
\text { dry weight }\end{array}$} \\
\cline { 2 - 3 } Organism tested & $5 \mathrm{hr}$. & $18 \mathrm{hr}$. \\
E. coli O1:K1:HNM & 0.97 & 0.27 \\
$E$. coli O2:K1:HNM & 1.15 & 0.46 \\
E. coli O7:K1:HNM & 1.82 & 0.23 \\
E. coli O16:K1:HNM & 1.69 & 0.19 \\
E. coli O25:K1:HNM & 1.23 & 0.11
\end{tabular}

Neuraminic acid content per bacterium of various Escherichia coli. Experiments were next performed to determine the content of neuraminic acid per bacterium in each of the different $\boldsymbol{E}$. coli of $\mathrm{KI}$ serotype isolated during the logarithmic phase of growth. In Table 5 are recorded typical values for content of neuraminic acid per bacterium for five different $E$. coli strains. The results clearly reveal that no gross differences exist in content of neuraminic acid per bacterium in the various strains analysed.

Isolation of colominic acid from Escherichia coli $01: K 1: H N M$ and $02: K 1: H N M$. Although strains of $\boldsymbol{E}$. coli which have a $\mathrm{Kl}$ serotype contain neuraminic acid, it was not known if the same derivative of this acid is present or whether the neuraminic acid derivative is in a chemical combination similar to that found in colominic acid obtained from $E$. coli $01: \mathrm{Kl}: \mathrm{HNM}$. Thus, a polysaccharide containing neuraminic acid was isolated from culture supernatants seeded with $E$. coli 02:Kl:HNM. The physical and chemical properties of this polysaccharide were compared with those of the polysaccharide, colominic acid, obtained from culture supernatants seeded with $E$. coli $\mathrm{O1}: \mathrm{K} 1: \mathrm{HNM}$.

Fifteen litres of culture medium (Barry, 1958) were seeded with $5 \times 10^{4}$ cells of Escherichia coli $\mathrm{O1}: \mathrm{K1}: \mathrm{HNM}$ or $\boldsymbol{E}$. coli $\mathrm{O} 2: \mathrm{K} 1: \mathrm{HNM}$ growing in the logarithmic phase. The culture was maintained at $37^{\circ}$ and aerated at the rate of 4 litres per min. for $18 \mathrm{hr}$. The $\mathrm{pH}$ of the culture was held at $7 \cdot 0$ by an electronic device (Goebel, 
Barry \& Shedlovsky, 1956). The culture was killed by addition of $100 \mathrm{ml}$. of chloroform and aeration continued for an additional $30 \mathrm{~min}$. The suspension was clarified in a Sharples Super centrifuge, refrigerated at $0^{\circ}-4^{\circ}$ by a cooling coil located within the bowl of the apparatus. The clear supernatant was concentrated at $20^{\circ}$ in vacuo to 1.5 1. in a glass circulating evaporator maintained at 1-2 mm. by means of a Kinney vacuum pump Model KC8. The fluid was fed into the evaporator with an electronic device (Barry \& Pierce, 1959) which maintained the liquid in the bowl of the evaporator at a constant level. The concentrated medium was dialysed by employing $5 \mathrm{ft}$. lengths of Nojax sausage casing (Visking Corp.) size 18/32, against distilled water for $16 \mathrm{hr}$. at $4^{\circ}$. The bag contents were concentrated in vacuo to $500 \mathrm{ml}$., dialysed, concentrated in vacuo to $100 \mathrm{ml}$. and redialysed. The solution was further concentrated to $100 \mathrm{ml}$. in vacuo, filtered and lyophilized. Yields of 5-5.5 g. of non-dialysable polysaccharide containing 20-30\% neuraminic acid were obtained.

Table 5. Neuraminic acid content of various Escherichia coli grown for 5 hr. at $37^{\circ}$

\begin{tabular}{|c|c|c|c|c|c|}
\hline Organism tested & $\begin{array}{c}\text { Titre } \\
\text { bacteria } \\
\text { per } \mathrm{ml} . \times 10^{8}\end{array}$ & $\begin{array}{l}\text { Volume } \\
\text { culture } \\
\text { (ml.) }\end{array}$ & $\begin{array}{c}\text { Total } \\
\text { number } \\
\text { of bacteria } \\
\left(\times 10^{11}\right)\end{array}$ & $\begin{array}{c}\text { Total } \\
\text { amount } \\
\text { neuraminic } \\
\text { acid } \\
\text { recovered } \\
\text { (mg.) }\end{array}$ & $\begin{array}{c}\text { Calculated } \\
\text { amount } \\
\text { neuraminic } \\
\text { acid } \\
\text { per } \\
\text { bacterium } \\
\left(\mu \mathrm{g} . \times 10^{-9}\right)\end{array}$ \\
\hline E. coli O1:K1:HNM & $\mathbf{3} \cdot \mathbf{3}$ & 482 & 1.59 & 1.94 & $12 \cdot 2$ \\
\hline E. coli O2:K1:HNM & $6 \cdot 2$ & 431 & 3.54 & $1 \cdot 68$ & 4.75 \\
\hline E. coli O7:K1:HNM & $7 \cdot 2$ & 433 & $3 \cdot 11$ & 2.17 & 6.96 \\
\hline E. coli O16:K1:HNM & $10 \cdot 0$ & 483 & $4 \cdot 83$ & 3.52 & $7 \cdot 30$ \\
\hline E. coli O25:K1:HNM & $4 \cdot 4$ & 505 & $\mathbf{2 \cdot 2 2}$ & $2 \cdot 80$ & $12 \cdot 6$ \\
\hline
\end{tabular}

A $3 \%(w / v)$ solution of the substance in $0.02 \mathrm{M}$-sodium acetate buffer was adjusted to $\mathrm{pH} 4.5$ and chilled to $4^{\circ}$. Absolute ethanol at $-10^{\circ}$ was added to a concentration of $75 \%(\mathrm{v} / \mathrm{v})$ and the solution stored for $2 \mathrm{hr}$. in the deep freeze at $-25^{\circ}$. The solution was centrifuged at $10,000 \mathrm{~g}$ at $-10^{\circ}$ in a Lourdes centrifuge and the supernatant decanted. The precipitate was dissolved in $100 \mathrm{ml}$. distilled water and the solution dialysed against $15 \mathrm{l}$. of water at $4^{\circ}$ for $16 \mathrm{hr}$. The solution was concentrated to $150 \mathrm{ml}$. in vacuo and filtered. The solution was stirred at room temperature and solid ammonium sulphate $(77 \cdot 7 \mathrm{~g}$.) was added to $75 \%$ saturation. After standing for $\mathbf{l ~ h r}$., the precipitate was removed by centrifugation and to the clear supernatant was added with stirring ammonium sulphate to $90 \%$ saturation (21.2 g.). One hr. later the solution was centrifuged. To the supernatant was added with stirring concentrated hydrochloric acid until incipient turbidity (approx. $0.15 \mathrm{ml}$.) and the solution filtered through a sintered glass filter of medium porosity. To the stirred filtrate was added additional concentrated hydrochloric acid until no more precipitate formed (approx. $0.9 \mathrm{ml}$.) and the solution kept at $4^{\circ}$ for $2 \mathrm{hr}$. The solution was filtered through a sintered glass filter of medium porosity and the sticky precipitate dissolved in $50 \mathrm{ml}$. distilled water. Two $\mathrm{ml}$. of $1 \mathrm{~N}$-hydrochloric acid was added and the solution dialysed until free of chloride and sulphate ions. The solution was concentrated to $50 \mathrm{ml}$. and traces of salt removed by electrodialysis. After concentrating the solution to $40 \mathrm{ml}$. in vacuo, it was filtered and lyophilized. Yields of $0 \cdot 5-1 \cdot 7 \mathrm{~g}$. of purified polysaccharide were obtained. 
Comparison of the properties of colominic acid obtained from Escherichia coli O1:K1:HNM with those of the polysaccharide containing neuraminic acid obtained from E. coli $O 2: K 1: H N M$

Purified colominic acid isolated from the $E$. coli 01 :K1:HNM culture supernatant and the purified polysaccharide, which contains neuraminic acid obtained from $E$. coli $\mathrm{O} 2: \mathrm{K} 1: H N M$, are white amorphous powders soluble in water. Aqueous solutions are markedly acidic $(\mathrm{pH} 3 \cdot 7)$ and not viscous. Humin is formed upon heating either substance in dilute mineral acid or by boiling in aqueous solution. Only feeble anthrone and Folin-Ciocalteu tests are given by either material. Hexosamines, pentoses and hexuronic acids are absent. Both substances give reddish purple colours when heated with Bial's orcinol or with Ehrlich's reagent. On the basis of the modified Ehrlich procedure, a typical analysis of colominic acid from E. coli 01:K1:HNM shows $99 \% \mathrm{~N}$-acetylneuraminic acid. A typical analysis of the polysaccharide containing neuraminic acid obtained from $E$. coli O2:K1:HNM shows $98.5 \% \mathrm{~N}$-acetylneuraminic acid. Neither substance precipitates in antiserum of rabbits immunized with the micro-organisms from which they are derived.

Table 6. Chemical analysis of polysaccharides containing neuraminic acid obtained from Escherichia coli $01: K 1: H N M$ and $02: K 1: H N M$

\begin{tabular}{|c|c|c|c|c|c|c|}
\hline \multirow[b]{2}{*}{ Source } & \multirow[b]{2}{*}{ Material analysed } & \multicolumn{4}{|c|}{ Substance analysed } & \multirow[b]{2}{*}{$\begin{array}{l}\text { Empirical } \\
\text { formula }\end{array}$} \\
\hline & & $\begin{array}{c}\mathbf{C} \\
(\%)\end{array}$ & $\begin{array}{c}\mathbf{H} \\
(\%)\end{array}$ & $\underset{(\%)}{N}$ & $\begin{array}{c}\mathrm{CH}_{3} \mathrm{CO} \\
(\%)\end{array}$ & \\
\hline E. coli O1:K1:HNM & Colominic acid & $42 \cdot 83$ & $6 \cdot 46$ & 4.79 & $14 \cdot 45$ & $\left(\mathrm{C}_{11} \mathrm{H}_{19} \mathrm{NO}_{\mathrm{g}}\right.$ \\
\hline E. coli O2:K1:HNM & Acidic polysaccharide & $42 \cdot 73$ & $6 \cdot 36$ & 4.71 & $13 \cdot 88$ & $\left(\mathrm{C}_{11} \mathrm{H}_{19} \mathrm{NO}_{8}\right.$ \\
\hline Sheep salivary mucin & $\begin{array}{l}N \text {-Acetylneuraminic } \\
\text { acid }\end{array}$ & $42 \cdot 72$ & $6 \cdot 19$ & $4 \cdot 53$ & $13 \cdot 92$ & $\left(\mathrm{C}_{11} \mathrm{H}_{19} \mathrm{NO}_{8}\right)$ \\
\hline
\end{tabular}

Chemical analyses. Analyses for carbon, hydrogen, nitrogen and acetyl were performed on several preparations of colominic acid obtained from Escherichia coli O1:K1:HNM and on the polysaccharide containing neuraminic acid obtained from $E$. coli $\mathrm{O} 2: \mathrm{K} 1: \mathrm{HNM}$. The materials were dried to constant weight at $80^{\circ}$. The results of typical analyses are given in Table 6. From the analytical data, the formula $\mathrm{C}_{11} \mathrm{H}_{19} \mathrm{NO}_{9}$ can be calculated as representing the monomer unit of both colominic acid and the acidic polysaccharide containing neuraminic acid obtained from E. coli $02: \mathrm{K1}$ :HNM. It should be mentioned that the empirical formula $\left(\mathrm{C}_{11} \mathrm{H}_{19} \mathrm{NO}_{9}\right)_{n}$ given for each of the polysaccharides includes a mole of bound water per $\mathrm{C}_{11} \mathrm{H}_{19} \mathrm{NO}_{9}$ unit.

The optical rotation of a $5 \%(\mathrm{w} / \mathrm{v})$ aqueous solution of colominic acid obtained from Escherichia coli 01:K1:HNM when measured in a $2 \mathrm{dm}$. tube, gave the value $[\alpha]_{\mathbb{D}}^{200}=-51^{\circ} \pm 2^{\circ}$. The optical rotation of the acidic polysaccharide obtained from $E$. coli $\mathrm{O} 2: \mathrm{K} 1: \mathrm{HNM}$ measured under identical conditions gave the value $[\alpha]_{\mathrm{D}}^{200}=-50^{\circ} \pm 2^{\circ}$.

Paper chromatographic analysis of the hydrolysate of either polysaccharide showed $N$-acetylneuraminic acid to be the major component (Barry, 1958).

An infra red absorption spectrum of colominic acid obtained from Escherichi acoli O1:K1:HNM and of the acidic polysaccharide obtained from $E$. coli O2:K1:HNM 
was taken in a potassium bromide pellet using $\mathbf{1 . 4} \mathbf{~ m g}$ of substance mixed with $350 \mathrm{mg}$. of the salt. The spectra are recorded in Fig. 1.

It is apparent from the elemental analytical data recorded in Table 6 and from the infrared absorption spectra shown in Fig. 1 that colominic acid isolated from the Escherichia coli $\mathrm{O1}: \mathrm{K1}: \mathrm{HNM}$ culture supernatants is similar in all respects to the polysaccharide containing neuraminic acid obtained from the $E$. coli O2:K1:HNM culture supernatants. Thus, it can be concluded that other strains of $\boldsymbol{E}$. coli which possess a K1 serotype and which contain neuraminic acid also elaborate colominic acid.

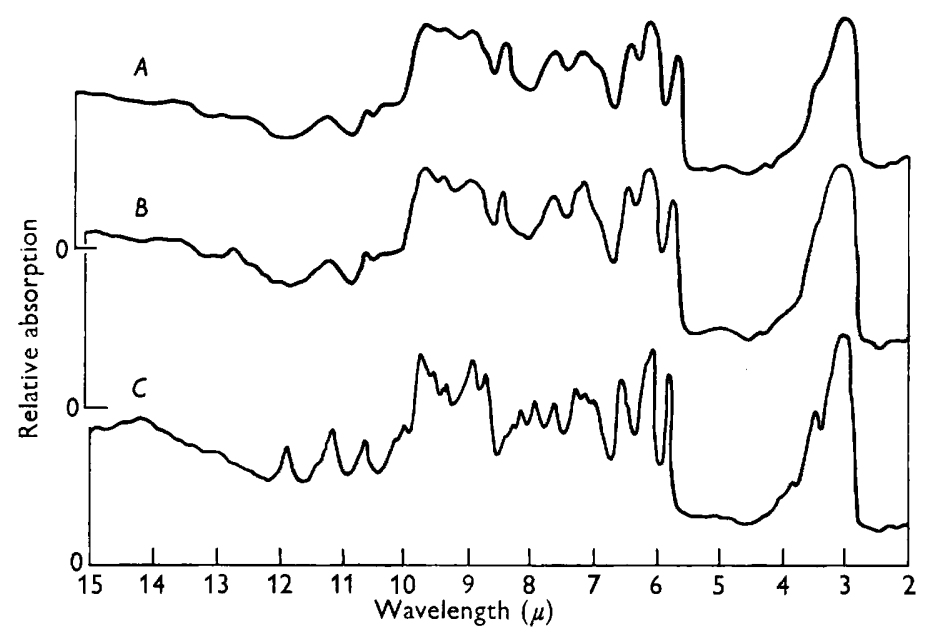

Fig. 1. Infrared spectrograms taken on $1.4 \mathrm{mg}$. of substance in $350 \mathrm{mg}$. of potassium bromide pellet. Curve $A$, colominic acid isolated from culture supernatant of $E$ scherichia coli O1:K1:HNM; Curve B, colominic acid isolated from culture supernatant of Escherichia coli $\mathrm{O} 2: \mathrm{K} 1: \mathrm{HNM}$; curve $C, N$-acetylneuraminic acid.

Chemical analysis of other species of bacteria for content of neuraminic acid. As derivatives of neuraminic acid have been found in only a few closely related enteric micro-organisms, it was of interest to determine if these substances were present in other enterobacteriaceae and in unrelated species of bacteria. As derivatives of neuraminic acid were first found in Escherichia coli, a genus of the enterobacteriaceae, it appeared that other genera of this family should be examined for the presence of these substances. Thus, 25 Salmonella, 7 Shigella, 2 Aerobacter aerogenes, a Citrobacter freundii and a strain of Klebsiella pneumoniae were analysed. Of these, only three strains, $S$. dahlem, S. djkarta and $C$. freundii, contain a neuraminic acid derivative in readily detectable quantities.

Negative tests for neuraminic acid were obtained for 3 strains of Bacillus megaterium, 2 of Bacillus cereus, 2 of Haemophilus influenzae type B and D and a strain of Rhodopseudomonas palustris. Two strains of Group C Neisseria meningitidis, 1908 and 1935, were analysed for content of neuraminic acid. These strains were reported to contain a derivative of neuraminic acid (Watson et al. 1958).

In Table 7 are recorded typical values found for content of neuraminic acid in various bacteria expressed as percentage of dry weight. The neuraminic acid content varies over a 20-fold range in concentraton. It is of interest to mention that the 
detection of neuraminic acid in the clarified and concentrated culture supernatants in which Salmonella dahlem, S. djkarta, Escherichia coli O1O:K5:HNM or Citrobacter freundii were grown was difficult and usually unsuccessful. Thus, it is concluded that these organisms do not readily elaborate polysaccharides which contain neuraminic acid into the culture medium as do strains of $E$. coli of $\mathrm{K} 1$ serotype.

Table 7. Neuraminic acid content of various bacteria grown at $37^{\circ}$ for $18 \mathrm{hr}$.

Organism tested

C. freundii 05:H80

S. dahlem

S. djkarta

N. meningitidis Group C 1908

N. meningitidis Group C 1935

E. coli O1O:K5:HNM

$\begin{gathered}\text { Neuraminic acid } \\ \% \text { dry weight }\end{gathered}$
$1 \cdot 92$
$1 \cdot 19$
$0 \cdot 51$
$0 \cdot 64$
$0 \cdot 26$
$0 \cdot 10$

Serological relationship of bacteria which contain neuraminic acid

As the neuraminic acid content of Salmonella dahlem, S. djkarta, Citrobacter freundii and Group C Neisseria meningitidis is of the same order of magnitude as is found in Escherichia coli of $\mathrm{Kl}$ serotype, it appeared that a colominic acid-like substance may be produced by these strains. In this connexion, it should be mentioned that the Group C hapten isolated from Group C $N$. meningitidis 1935 was reported to be $85 \%$ constituted of units of $N$-acetylneuraminic acid and to contain glucosamine (Watson et al. 1958). It was of interest, therefore, to determine by agglutination tests whether the various bacteria known to produce polysaccharides that contain neuraminic acid are related to each other.

The results of the agglutination experiments are recorded in Table 8 . It is apparent that Escherichia coli $01: \mathrm{K1}: \mathrm{HNM}$ and $02: \mathrm{K1}: \mathrm{HNM}$, which elaborate colominic acid, are unrelated to any of the other bacteria which contain neuraminic acid by cross-agglutination tests. However, $E$. coli $\mathrm{O1}: \mathrm{K1}: \mathrm{HNM}$ and O2:K1:HNM are related to each other. The strains of Group $\mathrm{C}$ Neisseria meningitidis are related to each other but to no other strain listed in Table 8. Salmonella dahlem, S. djkarta and Citrobacter freundii show an inter-relationship one to the other but are unrelated to either strain of $E$. coli or to the strains of Group C $N$. meningitidis. Thus, on the basis of the results of the agglutination experiments in homologous and heterologous antisera the strains examined can be divided into three separate and unrelated groups.

Precipitation of colominic acid and of Group $C$ Neisseria meningitidis hapten in homologous and heterologous antibacterial antisera. Despite the foregoing observations that no relationship was demonstrable by cross-agglutination tests between strains of Escherichia coli which elaborate colominic acid and strains of Group C Neisseria meningitidis which contain a polysaccharide constituted primarily of $\mathrm{N}$-acetylneuramic acid, experiments were performed to ascertain whether purified polysaccharides containing neuraminic acid obtained from these bacteria would precipitate in $\boldsymbol{E}$. coli and Group $\mathrm{C} \boldsymbol{N}$. meningitidis antibacterial antisera. The results of the precipitin tests are recorded in Table 9. It is apparent from the data that colominic acid does not precipitate in any of the antibacterial antisera, whereas the 
Group C N. meningitidis hapten readily precipitates in Group $\mathrm{C} N$. meningitidis antibacterial antisera, butnotin E. coli O1:K1:HNMor O2:K1:HNM antibacterial antisera.

Haemagglutination of human $O$ erythrocytes sensitized with adsorbed Group $C$ Neisseria meningitidis hapten or with colominic acid in homologous and heterologous antibacterial antisera. The incubation of erythrocytes in saline solutions of poly-

Table 8. Agglutination of bacteria which contain neuraminic acid in homologous and heterologous antisera

Dilution of antiserum

Organism tested

S. djkarta
S. dahlem

C. freundii

E. coli O1:K1:HNM

E. coli O2:K1:HNM

N. meningitidis 1908

N. meningitidis 1935

S. djkarta

S. dahlem

C. freundii

E. coli O1:K1:HNM

E. coli O2:K1:HNM

N. meningitidis 1908

N. meningitidis 1935

S. djkarta

S. dahlem

C. freundii

E. coli O1:K1:HNM

E. coli O2:K1:HNM

N. meningitidis 1908

N. meningitidis 1985

S. djkarta

S. dahlem

C. freundii

E. coli O1:K1:HNM

E. coli O2:K1:HNM

N. meningitidis 1908

N. meningitidis 1985

S. djkarta

S. dahlem

C. freundii

E. coli O1:K1:HNM

E. coli O2:K1:HNM

N. meningitidis 1908

N. meningitidis 1985

S. djkarta

S. dahlem

C. freundii

E. coli 01:K1:HNM

E. coli O2:K1:HNM

N. meningitidis 1908

N. meningitidis 1985

S. djkarta

S. dahlem

C. freundii

E. coli O1:K1:HNM

E. coli O2:K1:HNM

N. meningitidis 1908

N. meningitidis 1935

S. dahlem

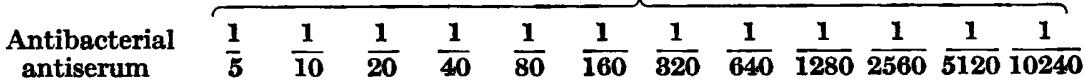

S. djkarta

S. dahlem

C. freundii

.

E. coli

O1:K1:HNM

4
4
4
0
0
0
0

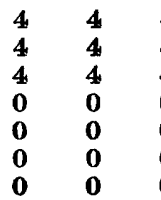

$\mathbf{4}$
$\mathbf{4}$
$\mathbf{4}$
$\mathbf{0}$
$\mathbf{0}$
$\mathbf{0}$
$\mathbf{0}$

$\mathbf{4}$
$\mathbf{4}$
$\mathbf{3}$
$\mathbf{0}$
$\mathbf{0}$
$\mathbf{0}$
$\mathbf{0}$

$\begin{array}{ll}\mathbf{4} & 4 \\ \mathbf{4} & \mathbf{2} \\ \mathbf{2} & \mathbf{0} \\ \mathbf{0} & 0 \\ \mathbf{0} & \mathbf{0} \\ \mathbf{0} & \mathbf{0}\end{array}$

$\begin{array}{ll}\mathbf{4} & \mathbf{4} \\ \mathbf{2} & \mathbf{1} \\ \mathbf{0} & \mathbf{0} \\ \mathbf{0} & \mathbf{0} \\ \mathbf{0} & \mathbf{0} \\ \mathbf{0} & \mathbf{0} \\ \mathbf{0} & \mathbf{0}\end{array}$

$\begin{array}{lllll}\mathbf{4} & \mathbf{4} & \mathbf{1} & \mathbf{\pm} & \mathbf{0} \\ \mathbf{1} & \mathbf{\pm} & \mathbf{0} & \mathbf{0} & \mathbf{0} \\ \mathbf{0} & \mathbf{0} & \mathbf{0} & \mathbf{0} & \mathbf{0} \\ \mathbf{0} & \mathbf{0} & \mathbf{0} & \mathbf{0} & \mathbf{0} \\ \mathbf{0} & \mathbf{0} & \mathbf{0} & \mathbf{0} & \mathbf{0} \\ \mathbf{0} & \mathbf{0} & \mathbf{0} & \mathbf{0} & \mathbf{0} \\ \mathbf{0} & \mathbf{0} & \mathbf{0} & \mathbf{0} & \mathbf{0}\end{array}$

4

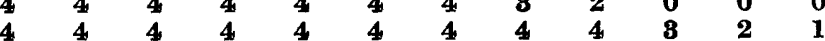

$\begin{array}{llllllllllll}4 & 4 & 4 & 4 & 4 & 2 & \pm & 0 & 0 & 0 & 0 & 0\end{array}$

$\begin{array}{llllllllllll}0 & 0 & 0 & 0 & 0 & 0 & \mathbf{0} & 0 & 0 & 0 & 0 & 0\end{array}$

$\begin{array}{llllllllllll}\mathbf{0} & \mathbf{0} & \mathbf{0} & \mathbf{0} & \mathbf{0} & \mathbf{0} & \mathbf{0} & \mathbf{0} & \mathbf{0} & \mathbf{0} & \mathbf{0} & \mathbf{0} \\ \mathbf{0} & \mathbf{0} & \mathbf{0} & \mathbf{0} & \mathbf{0} & \mathbf{0} & \mathbf{0} & \mathbf{0} & \mathbf{0} & \mathbf{0} & \mathbf{0} & \mathbf{0}\end{array}$

0 1000

4.

$\begin{array}{llllllllll}4 & 4 & 4 & 4 & 4 & 4 & 4 & 1 & 0 & 0\end{array}$

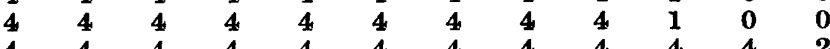

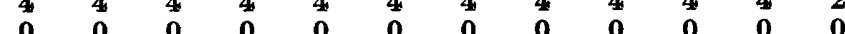

$\begin{array}{llllllllllll}0 & 0 & 0 & 0 & 0 & 0 & 0 & 0 & 0 & 0 & 0 & 0\end{array}$

$\begin{array}{llllllllllll}\mathbf{0} & \mathbf{0} & \mathbf{0} & \mathbf{0} & \mathbf{0} & \mathbf{0} & \mathbf{0} & \mathbf{0} & \mathbf{0} & \mathbf{0} & \mathbf{0} & \mathbf{0} \\ \mathbf{0} & \mathbf{0} & \mathbf{0} & \mathbf{0} & \mathbf{0} & \mathbf{0} & \mathbf{0} & \mathbf{0} & \mathbf{0} & \mathbf{0} & \mathbf{0} & \mathbf{0}\end{array}$

(a)

E. coli

O2:K1:HNM

N. meningitidis

Group C 1808

N.

N. meningitidis

Group C 1985

$\mathbf{0}$

$\begin{array}{lllllll}\mathbf{0} & \mathbf{0} & \mathbf{0} & \mathbf{0} & \mathbf{0} & \mathbf{0} & \mathbf{0}\end{array}$

$\begin{array}{llllllllllll}\mathbf{0} & \mathbf{0} & \mathbf{0} & \mathbf{0} & \mathbf{0} & \mathbf{0} & \mathbf{0} & \mathbf{0} & \mathbf{0} & \mathbf{0} & \mathbf{0} & \mathbf{0}\end{array}$

$\begin{array}{llllllllllll}4 & 4 & 4 & 4 & 3 & 2 & \pm & 0 & 0 & 0 & 0 & 0\end{array}$

$\begin{array}{llllllllllll}4 & 4 & 4 & 4 & 2 & 1 & \overline{0} & 0 & 0 & 0 & 0 & 0\end{array}$

$\begin{array}{llllllllllll}\mathbf{0} & \mathbf{0} & \mathbf{0} & \mathbf{0} & \mathbf{0} & \mathbf{0} & \mathbf{0} & \mathbf{0} & \mathbf{0} & \mathbf{0} & \mathbf{0} & \mathbf{0} \\ \mathbf{0} & \mathbf{0} & \mathbf{0} & \mathbf{0} & \mathbf{0} & \mathbf{0} & \mathbf{0} & \mathbf{0} & \mathbf{0} & \mathbf{0} & \mathbf{0} & \mathbf{0}\end{array}$

o

$\begin{array}{lllll}\mathbf{0} & \mathbf{0} & \mathbf{0} & \mathbf{0} & \mathbf{0} \\ \mathbf{0} & \mathbf{0} & \mathbf{0} & \mathbf{0} & \mathbf{0}\end{array}$

$\begin{array}{lllllllll}\mathbf{0} & \mathbf{0} & \mathbf{0} & \mathbf{0} & \mathbf{0} & \mathbf{0} & \mathbf{0} & \mathbf{0} & \mathbf{0} \\ \mathbf{4} & \mathbf{0} & \mathbf{0} & \mathbf{0} & \mathbf{0} & \mathbf{0} & \mathbf{0} & \mathbf{0} & \mathbf{0}\end{array}$

$\begin{array}{llll}4 & 4 & 2 & \pm \\ 4 & 4 & 4 & 2\end{array}$

$\begin{array}{llll}\mathbf{0} & \mathbf{0} & \mathbf{0} & \mathbf{0} \\ \mathbf{0} & \mathbf{0} & \mathbf{0} & \mathbf{0}\end{array}$

0
\pm

$\mathbf{0}$

o 
saccharides frequently leads to the adsorption of these substances to the cell surface. Addition of antiserum prepared against the polysaccharide to a suspension of the sensitized erythrocytes results in their haemagglutination. This sensitive

Table 9. Precipitin tests of colominic acid and Neisseria meningitidis Group $C$ hapten in E. coli O1:K1:HNM, O2:K1:HNM and N. meningitidis Group C 1908 and 1935 antisera.

Substance tested
Colominic acid

N. meningitidis

Group C 1908 hapten

Antiserum
E. coli O1:K1:HNM
E. coli O2:K1:HNM
N. meningitidis 1908
N. meningitidis 1935
E. coli O1:K1:HNM
E. coli O2:K1:HNM
N. meningitidis 1908
N. meningitidis 1985

\begin{tabular}{cccccc}
\multicolumn{5}{c}{ Concentration of substance $(\mu \mathrm{g} . / \mathrm{ml})$} \\
$\mathbf{1 0 0 0}$ & 100 & 10 & 1 & $0 \cdot 1$ & $0 \cdot 01$ \\
0 & 0 & 0 & 0 & 0 & 0 \\
0 & 0 & 0 & 0 & 0 & 0 \\
0 & 0 & 0 & 0 & 0 & 0 \\
0 & 0 & 0 & 0 & 0 & 0 \\
0 & 0 & 0 & 0 & 0 & 0 \\
0 & 0 & 0 & 0 & 0 & 0 \\
4 & 3 & 2 & 1 & 0 & 0 \\
4 & 3 & 2 & 1 & 0 & 0
\end{tabular}

4 , heavy precipitation. 0 , no precipitation

Table 10. Haemagglutination of type $O$ erythrocytes sensitized with Neisseria meningitidis Group $C$ hapten or colominic acid in N. meningitidis Group $C$ 1908, 1935, Escherichia coli $O 1: K 1: H N M$ and $02: K 1: H N M$ antisera

Dilution of antiserum

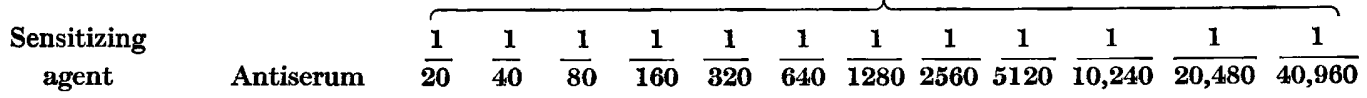

N. meningitidis $\quad$ N. meningitidis

$\begin{array}{lllllllllllllllll}\text { Group C. hapten Group C } 1908 & 4 & 4 & 4 & 4 & 4 & 4 & \mathbf{3} & \mathbf{3} & \mathbf{1} & \mathbf{1} & \mathbf{0} & \mathbf{0}\end{array}$

$\begin{array}{lllllllllllllll} & 1935 & 4 & 4 & 4 & 4 & 4 & 3 & 2 & 2 & 1 & 0 & 0 & 0 \\ \text { E. coli } & & & & & & & & & & & & \\ \text { O1:K1:HNM } & 0 & 0 & 0 & 0 & 0 & 0 & 0 & 0 & 0 & 0 & 0 & 0 \\ \text { O2:K1:HNM } & 0 & 0 & 0 & 0 & 0 & 0 & 0 & 0 & 0 & 0 & 0 & 0\end{array}$

Colominic acid N. meningitidis

$\begin{array}{lllllllllllll}\text { Group C 1908 } & \mathbf{0} & \mathbf{0} & \mathbf{0} & \mathbf{0} & \mathbf{0} & \mathbf{0} & \mathbf{0} & \mathbf{0} & \mathbf{0} & \mathbf{0} & \mathbf{0} & \mathbf{0} \\ \mathbf{1 9 3 5} & \mathbf{0} & \mathbf{0} & \mathbf{0} & \mathbf{0} & \mathbf{0} & \mathbf{0} & \mathbf{0} & \mathbf{0} & \mathbf{0} & \mathbf{0} & \mathbf{0} & \mathbf{0} \\ \boldsymbol{E} . \text { coli } & & & & & & & & & & & & \\ \text { O1:K1:HNM } & \mathbf{0} & \mathbf{0} & \mathbf{0} & \mathbf{0} & \mathbf{0} & \mathbf{0} & \mathbf{0} & \mathbf{0} & \mathbf{0} & \mathbf{0} & \mathbf{0} & \mathbf{0} \\ \text { O2:K1:HNM } & \mathbf{0} & \mathbf{0} & \mathbf{0} & \mathbf{0} & \mathbf{0} & \mathbf{0} & \mathbf{0} & \mathbf{0} & \mathbf{0} & \mathbf{0} & \mathbf{0} & \mathbf{0}\end{array}$

4, complete haemagglutination. 0 , no haemagglutination.

test is employed for the demonstration of materials which have weak serological properties. Thus, fresh human $\mathrm{O}$ erythrocytes were incubated with saline solutions of purified colominic acid or with Group C Neisseria meningitidis 1908 hapten. Sensitized cells were then added to Escherichia coli O1:KI:HNM, E. coli O2:K1:HNM, Group C N. meningitidis 1908 and 1935 antibacterial antisera. The results are given in Table 10 where it is to be noted that erythrocytes sensitized with the Group $\mathrm{C} N$. meningitidis hapten are readily agglutinated in $N$. meningitidis antibacterial antiserum prepared against either the 1908 or 1935 strains. However, these cells are not agglutinated in antisera prepared against $E$. coli 01:K1:HNM 
or $\boldsymbol{E}$. coli $\mathrm{O} 2: \mathrm{K} 1: \mathrm{HNM}$. In the experiments where cells sensitized with colominic acid were used, no haemagglutination occurred in any of the four antisera. Thus, no serological relationship was demonstrable between colominic acid and the Group C $N$. meningitidis hapten.

Table 11. Inhibition of haemagglutination by colominic acid of type $O$ erythrocytes sensitized with Neisseria meningitidis Group $C 1908$ hapten in N. meningitidis Group C 1908 antiserum

\begin{tabular}{|c|c|c|c|c|c|c|c|c|c|c|}
\hline \multirow[t]{2}{*}{ Inhibitor } & \multirow{2}{*}{$\begin{array}{c}\text { Inhibitor } \\
\text { concentra- } \\
\text { tion } \\
(\mu \mathrm{g} . / \mathrm{ml} .)\end{array}$} & \multicolumn{9}{|c|}{ Dilution of antiserum } \\
\hline & & $1 / 20$ & $1 / 40$ & $1 / 80$ & $1 / 160$ & $1 / 320$ & $1 / 640$ & $1 / 1280$ & $1 / 2560$ & $1 / 5120$ \\
\hline \multirow[t]{5}{*}{ Colominic acid } & 10,000 & 4 & 4 & 4 & 4 & 4 & 4 & $\mathbf{3}$ & 2 & $\mathbf{0}$ \\
\hline & 2,000 & 4 & 4 & 4 & 4 & 4 & 4 & 3 & $\mathbf{1}$ & $\mathbf{0}$ \\
\hline & 400 & 4 & 4 & 4 & 4 & 4 & 4 & 2 & 1 & 0 \\
\hline & 100 & 4 & 4 & 4 & 4 & 4 & 4 & $\mathbf{3}$ & 1 & 0 \\
\hline & 0 & 4 & 4 & 4 & 4 & 4 & 3 & 3 & 1 & 0 \\
\hline
\end{tabular}

4, complete haemagglutination. 0 , no haemagglutination

Inhibition of haemagglutination of human type O erythrocytes sensitized with Group C Neisseria meningitidis 1908 hapten by colominic acid. Despite the observation that human type $\mathrm{O}$ erythrocytes sensitized with Group C N. meningitidis 1908 hapten failed to haemagglutinate in Escherichia coli $01: \mathrm{K} 1: \mathrm{HNM}$ or $E$. coli O2:K1:HNM antisera, it appeared that a relationship between colominic acid and the Group $\mathbf{C}$ $N$. meningitidis hapten might be demonstrable by employing a haemagglutination blocking method where $N$. meningitidis antiserum is incubated with colominic acid prior to the addition of erythrocytes sensitized with Group C N. meningitidis 1908 hapten. The results are shown in Table 11, where it is seen that no inhibition of the haemagglutination of the erythrocytes sensitized with Group $\mathrm{C} N$. meningitidis hapten occurs in any of the incubated antisera containing colominic acid. Therefore, it is concluded that colominic acid does not combine with antibody present in Group C $N$. meningitidis antibacterial antiserum which precipitates Group $\mathrm{C} N$. meningitidis 1908 hapten.

\section{DISCUSSION}

The discovery of the neuraminic acids in materials derived from mammalian origin (Blix, 1936) laid the foundation for a new field of biochemistry. Many animal tissues contain derivatives of neuraminic acid in combination with carbohydrates, lipids and proteins. The wide distribution of neuramino-mucoproteins in animal secretions and excretions suggests that these materials have a protective function in cells. The epithelial surfaces of the respiratory, digestive and urogenital tracts are covered by mucins rich in neuramino-proteins. Certain bacteria and viruses which inhabit or invade these tracts possess neuraminidases which can split neuraminic acid from neuramino-proteins and thus a possible mechanism of invasion of underlying cells by these agents is indicated. The discovery of substances containing neuraminic acid in materials derived from bacteria opened up a new area in the biochemistry of bacteria. However, the distribution and biological significance of neuraminic acid in bacteria has remained largely unknown. 
The work presented here has shown that few strains of Gram-negative bacteria contain readily detectable amounts of neuraminic acid. Among the 70 different Gram-negative micro-organisms analysed, only 11 contain neuraminic acid. Of these, 6 are Escherichia coli, 2 are Salmonella, 2 are Group $\mathrm{C}$ Neisseria meningitidis and one is a Citrobacter freundii. It is of interest to note that the strains which contain neuraminic acid were isolated from pathological material obtained from mammalian sources. The incorporation of neuraminic acid derivatives in complex bacterial products, approaching the host neuramino-mucoproteins' composition, may be the microbe's method of establishing itself in various tissues. However the virulence of strains of $\boldsymbol{E}$. coli containing neuraminic acid was shown by Forbes $\&$ Kunk (1961) to be no greater than that of strains which do not contain this material.

The development of a systematic classification scheme for the enterobacteriaceae, based on the antigenic composition of the micro-organisms, has made it possible to identify enterobacteriaceae isolated from different sources. The determination of the serotype of Escherichia coli $\mathrm{K235L}+\mathrm{OC}^{+}$as $01: \mathrm{K1}: \mathrm{HNM}$ was of considerable value in the finding of other $E$. coli which produce colominic acid (poly $N$-acetylneuraminic acid) and to a determination of the relationship of colominic acid to other properties of these bacteria. Thus, the isolation of colominic acid from culture supernatants of different $E$. coli which possess a $K 1$ but different $O$ serotypes, namely $E$. coli $\mathrm{O} 1: \mathrm{K} 1: \mathrm{HNM}$ and $E$. coli $\mathrm{O} 2: \mathrm{K} 1: \mathrm{HNM}$, strongly suggests that other $\boldsymbol{E}$. coli which contain neuraminic acid and have a $\mathrm{Kl}$ serotype also produce colominic acid (Barry et al. 1960). This view is further supported by the observation that 5 strains of $E$. coli with a $\mathrm{K} 1$ but different $\mathrm{O}$ serotypes contain equivalent amounts of neuraminic acid. Furthermore, the absence of neuraminic acid in E. coli which have other $\mathrm{K}$ serotypes demonstrates that this material is not a common component of strains which possess a $\mathrm{K}$ serotype. The association of the $\mathrm{K} 1$ antigen of $E$. coli with colominic acid is evident and it suggests that the genes which control the biosynthesis of these materials are closely linked. Finally, it was shown that other properties of $E$. coli, such as ability to produce haemolysins or bacteriocines, cannot be directly associated with the production of colominic acid or the presence of neuraminic acid. The earlier observations (Barry, 1958) and those reported here concerning the close association of neuraminic acid with a $\mathrm{Kl}$ serotype in various strains of $E$. coli were recently confirmed (De Witt \& Rowe, 1961; De Witt \& Zell, 1961).

The detection of neuraminic acid in species of bacteria other than Escherichia coli suggested that colominic acid may be produced by these micro-organisms. The crossagglutination experiments clearly revealed that no serological relationship exists between $E$. coli which elaborate colominic acid and other micro-organisms which contain neuraminic acid. The strain of Citrobacter freundii which is constituted of $1.9 \%$ neuraminic acid does not possess a $\mathrm{K}$ antigen but has $\mathrm{O}$ and $\mathrm{H}$ antigens which are related to the $\mathrm{O5}$ and $\mathrm{H3O}$ antigens present in bacteria of the Arizona group of enterobacteriaceae. Although it is possible to detect the presence of neuraminic acid in complex materials isolated from the culture supernatants of $C$. freundii 05:H3O, it is apparent that the greater portion of the neuraminic acid is firmly bound. On the other hand, strains of $E$. coli which produce colominic acid readily elaborate this material into the culture medium. These results indicate a different chemical binding of the neuraminic acid in C. freundii and in the related strains Salmonella dahlem and S. djkarta. 
In 1958, subsequent to the discovery of colominic acid, Watson \& Scherp (1958) described the isolation and characterization of the group $\mathrm{C}$ hapten obtained from Group C Neisseria meningitidis. This material was reported to be constituted of units of $\mathrm{N}$-acetylneuraminic acid to the extent of $70-85 \%$ and to contain glucosamine (Watson et al. 1958). The Group C hapten is serologically active, whereas colominic acid is not. All experiments reported here have failed to show any serological relationship between colominic acid and the Group $\mathrm{C} N$. meningitidis hapten. It must be concluded, therefore, that these two substances have either a different arrangement of the $\mathrm{N}$-acetylneuraminic acid units within the macromolecule or that the serological properties of the Group C N. meningitidis hapten are attributable to factors other than the neuraminic acid portion of the polysaccharide.

Neuraminic acid materials are present in three genera of the enterobacteriaceae family; however, the detection of these substances has been made in only a few strains. The detection of neuraminic acid in a genus of the neisseriaceae has shown that complex substances which contain neuraminic acid also exist in bacteria of other families.

It is not yet possible to assess fully the biological importance or function of neuraminic acid in bacteria. Furthermore, little can be said about the biosynthesis or metabolism of neuraminic acid in cells. It is apparent, therefore, that information concerning the distribution and nature of the chemical binding of neuraminic acid in micro-organisms is desirable, for this will provide the means for further investigations.

From the data which have been discussed, it is concluded that colominic acid (poly $\mathrm{N}$-acetylneuraminic acid) is produced by Escherichia coli strains which possess a K1 serotype. Other bacteria which contain neuraminic acid have this substance in a chemical combination which is different from that of colominic acid.

This work was supported by a grant from the United States Public Health Service, National Institutes of Health, E2327.

The author is indebted to Dr W. H. Ewing of the United States Public Health Service for the determination of the serotype of Escherichia coli $\mathrm{K}_{235 \mathrm{~L}}+\mathrm{OC}^{+}$as E. coli $01: \mathrm{K1}: \mathrm{HNM}$ and of $\boldsymbol{E}$. coli $5396 / 38$ as a Citrobacter freundii with $\mathrm{O}$ and $\mathbf{H}$ antigens related to $\mathrm{O5}$ and $\mathrm{H3O}$ antigens present in the Arizona group of the enterobacteriaceae.

\section{REFERENCES}

Adams, M. H. (1950). Methods of study of bacterial viruses. In Methods in Med. Research (ed. J. M. Comroe), vol. 2. Chicago: Year Book Publishers.

BARRY, G. T. (1957). The isolation of $N$-acetylneuraminic acid from colominic acid. Science, 126, 1230.

Barry, G. T. (1958). Colominic acid, a polymer of $\mathrm{N}$-acetylneuraminic acid. J. exp. Med. 107, 507.

BARRY, G. T. (1959). Detection of sialic acid in various Escherichia coli strains and in other species of bacteria. Nature, Lond. 183, 117.

Barry, G. T. \& Pierce, F. (1959). Automatic feed device for laboratory size glass circulating evaporator. J. biochem. Microbiol. Tech. Engng, 1, 297.

Barry, G. T., Tsai, T. \& Chen, F. P. (1960). Chemical and serological relationships of certain bacterial polysaccharides containing sialic acid. Nature, Lond. 185, 597. 
Bux, G. (1936). Über die Kohlenhydratgruppen des Submaxillarismucins. Hoppe-Seyl. Z. $240,43$.

Cummins, C. S. \& Harris, H. (1956). Differences in cell wall composition among Gram positive cocci and bacilli. J. gen. Microbiol. 14, 583.

DE WrTt, C. W. \& Rowe, J. A. (1961). Sialic acids ( $N$, 7-0-diacetylneuraminic acid and $\mathrm{N}$-acetylneuraminic acid) in Escherichia coli. I. Isolation and identification. J. Bact. 82, 838.

De WitT, C. W. \& ZELL, E. A. (1961). Sialic acids ( $N$, 7-0-diacetylneuraminic acid and $\mathrm{N}$-acetylneuraminic acid) in Escherichia coli. II. Their presence on the cell wall surface and relationship to $\mathrm{K}$ antigen. J. Bact. 82, 849.

Dische, Z. (1947). A new specific color reaction of hexuronic acids. J. biol. Chem. 167, 189.

Dische, Z., Shetrles, L. B. \& Osnos, M. (1949). New specific color reactions of hexoses and spectrophotometric micromethods for their determination. Arch. Biochem. 22, 169.

EDWards, P. R. (1951). Preparation of antisera for detection of somatic antigens of Salmonella cultures. Pub. Hlth Rep., Wash. 66, 837.

EDwards, P. R. \& Ewing, W. H. (1955). Identification of Enterobacteriaceae. Minneapolis: The Burgess Publishing Co.

Forbes, M. \& KUNK, N. A. (1961). Lack of relationship between sialic acid content, toxicity, and lethality of Escherichia coli. Proc. Soc. exp. Biol., N.Y. 108, 34.

Gokbel, W. F., Barry, G. T. \& Shedlovsky, T. (1956). Colicine K. I. The production of colicine $\mathrm{K}$ in media maintained at constant $\mathrm{pH}$. J. exp. Med. 103, 577.

GoEres, W. F. \& Barry, G. T. (1958). Colicine K. II. The preparation and properties of a substance having colicine $\mathrm{K}$ activity. J. exp. Med. 107, 185.

KaUfrmanN, F. (1943). Ǔber neue thermolabile Körperantigene der Coli-Bakterien. Acta path. microbiol. scand. 20, 21.

KunKel, H. G. \& Trselrus, A. (1951). Electrophoresis of proteins on filter paper. J. gen. Physiol. 35, 89.

LANDY, M. \& LAMB, E. (1953). Estimation of Vi antibody employing erythrocytes treated with purified Vi antigen. Proc. Soc. exp. Biol., N.Y. 82, 593.

NETER, E. (1947). The effect of yeast concentrate on the growth and survival of Hemophilus influenzae in fusion broth. J. Bact. 54, 70.

RAKE, G. (1933). Studies on meningococcus infection. J. exp. Med. 57, 561.

SoRENSEN, M. (1938). On the determination of glucosamine in proteins. C.R. Lab. Carlsberg. 22, 487.

Strange, R. E. \& Powell, J. F. (1954). Hexosamine containing peptides in spores of Bacillus subtilis, B. megatherium and B. cereus. Biochem. J. 58, 80.

Watson, G. R. \& Scherp, H. W. (1958). The specific hapten of Group C (Group II $\alpha$ ) meningococcus. I. Preparation and immunological behaviour. J. Immunol. 81, 331 .

Watson, G. R., Martinetti, G. V. \& Scherp, H. W. (1958). The specific hapten of Group C (Group II $\alpha$ ) meningococcus. II. Chemical nature. J. Immunol. 81, 337.

WERNER, I. \& ODIN, L. (1952). On presence of sialic acid in certain glycoproteins and in gangliosides. Acta Soc. med. upsalien. 57, 230.

Westphal, O., KauffmanN, F., Lüderitz, O. \& Stierlin, H. (1960). Zur Immunochemie der O-Antigene von Enterobacteriaceae. Zbl. Bakt. (I. Abt. Orig.), 179, 336. 